\title{
Things learned in early adulthood are remembered best
}

\author{
DAVID C. RUBIN and TAMARA A. RAHHAL \\ Duke University, Durham, North Carolina \\ and \\ LEONARD W. POON \\ University of Georgia, Athens, Georgia
}

\begin{abstract}
Evidence is reviewed that for older adults the period from 10 to 30 years of age produces recall of the most autobiographical memories, the most vivid memories, and the most important memories. It is the period from which peoples' favorite films, music, and books come and the period from which they judge the most important world events to have originated. Factual, semantic, general-knowledge, multiple-choice questions about the Academy Awards, the World Series, and current events from this period were answered more accurately by two different groups of 30 older adults tested 10 years apart. A cognitive theory based on the importance of transitions and several noncognitive theories are considered as explanations of this pervasive phenomenon.
\end{abstract}

Adolescence and early adulthood are special times for memory encoding. There is solid evidence that people recall a disproportionate number of autobiographical memories from that period when they are asked to recall important events, or recall vivid memories, or recall the first event that comes to mind when they are cued by a word. There is also some evidence, which we will add to here, that people answer general-knowledge, semantic-memory questions more accurately if the questions are about information that they have learned during those years. Adolescence and early adulthood are special in other ways. In our culture, it is when people come of age, when their place in society is formed. It is a time of identity formation (Erikson, 1950). It is the time of their generation (Schuman \& Scott, 1989), their era (Sehulster, 1996). Things were better then, or at least more vivid and exciting. It is the time for which we have the most nostalgia (Holbrook, 1993). As Sehulster (1996, p. 146) notes, "You all know that the regulars on Saturday Night Live during your era were funnier than they are now. Who was the host of your Tonight Show? Steve Allen? Jack Paar? Johnny Carson? or Jay Leno? Who was your James Bond? Sean Connery? Roger Moore? Timothy Dalton? Who was your Isolde? Kirsten Flagstad? Helen Traubel? Birgit Nilsson? Hildegard Behrens?"

We wish to thank Martin Crim for his help in formulating the questions, the Associated Press for allowing us to use their copyrighted material for scientific purposes, and Martin Conway, Fergus Craik, Herb Crovitz, Gregory Kimble, Gregory Lockhead, David Pillemer, Charles Thompson, and the 1994 Swiss Course on the Psychology of Memory for their suggestions. A version of this paper was presented at the 1995 Annual Meeting of the Society for Applied Research in Memory and Cognition. Support was provided by NIA Grant AG04278 and the Duke University Arts and Science Research Council. Reprints are available from D. C. Rubin, Experimental Psychology, Duke University, Durham NC 27708-0086 (e-mail: rubin(apsych.duke.edu).
In this paper, we will first review the autobiographicalmemory and preference literature in order to document that events or activities that occur between the ages of 10 and 30 are recalled more often and judged to be more important or better than events or activities from other age periods. This increase in performance with respect to, or preference for, the time between the ages of 10 and 30 constitutes what may be called a bump, and we will also describe the range of phenomena for which this bump exists. Next, we will describe a study in which we used objective five-choice questions about three domains of public information in order to extend this finding to the recall of semantic, general-knowledge factual information. We will suggest four accounts, based on different approaches in psychology, of why this bump in memory and preference might occur. Thus, we will first document and extend the existence of the phenomenon and only then try to understand it (Rubin, 1989; Rubin \& Wenzel, 1996). We have chosen to do this in part because although theories have been put forth to explain the bump in autobiographical memory and other domains, the bump occurs in a range of situations, and it seems parsimonious to consider theories that could account for all the data. For instance, showing that the bump occurs for factual, semantic memory calls into question the completeness of theories that explain the bump only for autobiographical memory or preference.

Most of our empirical evidence will be presented graphically. To make comparisons among figures easier, we have kept the age range in all the figures at the same 0 - to 80 -year range, and we always start the $y$-axis from a true zero whenever there is one. We have also converted the data sets reported in number of events per time period to percentages so that the area under all such curves is the same $100 \%$. This standard form produces less dramatic plots than does adjusting the axes for each curve, but it facili- 


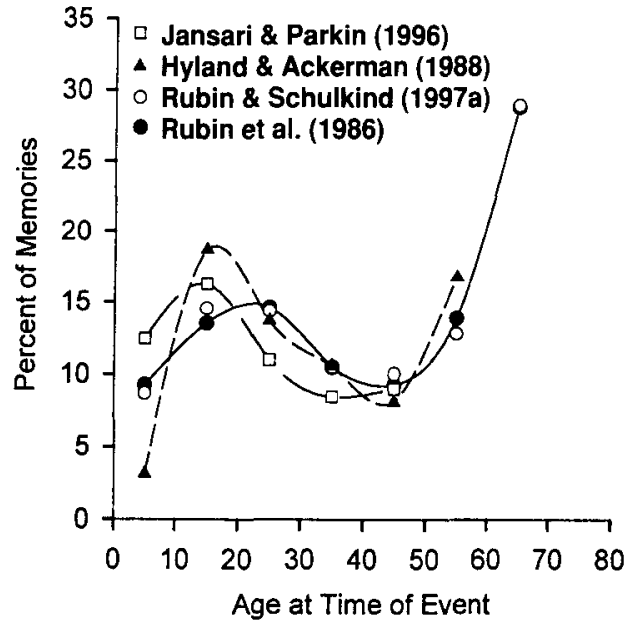

Figure 1. Distribution of autobiographical memories from older adults as a function of reported age at time of the event.

tates direct quantitative comparisons among both the temporal extent and the magnitude of any effects.

\section{Evidence for Enhanced Recall of Autobiographical Memories from Early Adulthood}

Evidence shows that autobiographical memories from early adulthood are remembered best. In older adults, there are more autobiographical memories from the 10-to30 age period, which can be seen from a review of the research. There was a revival in the experimental analysis of autobiographical memory following Crovitz and Schiffman's (1974) reintroduction of Galton's (1879) procedure for cuing autobiographical memories with words (for reviews, see Conway, 1990; Conway \& Rubin, 1993; Conway, Rubin, Spinnler, \& Wagenaar, 1992; Rubin, 1986, 1996). Figure 1 presents the percentage of autobiographical memories from each decade of life, from four studies in which Galton's cue-word technique was used. One plot, from Rubin, Wetzler, and Nebes (1986), represents a total of 1,373 autobiographical memories obtained from 70 adults who were about 70 years old. They were tested in three different laboratories under slightly different conditions (Fitzgerald \& Lawrence, 1984; Franklin \& Holding, 1977; Rubin et al., 1986). At the time of data collection, none of the researchers in these laboratories were expecting a nonmonotonic function, which only appeared on reanalysis of the data. In all cases, the volunteers were asked to provide the autobiographical memory cued by each of between 20 and 50 words. On completing this, they were asked to date each memory. Roughly half the memories produced by these volunteers are not in Figure 1. These memories had occurred within the most recent year of life, and to include them in the plot would have meant that the vertical axis would have had to have been expanded, making the rest of the curve less visible. Rubin et al. (1986) plotted similar curves for 40-, 50-, and 60-year-old subjects based on data from the same three laboratories and one more (Zola-Morgan, Cohen, \& Squire, 1983). Only the 40-year-old subjects did not show the bump that can be seen in the Figure.

Another study plot in Figure 1, which has been fit with the use of the same curve as that for the Rubin et al. (1986) points, is from Rubin and Schulkind (1997a). Twenty 70year-old volunteers were cued for autobiographical memories with 124 words. Again all memories dated within 1 year of the experimental session were excluded, leaving 1,093 dated memories. The two studies provide similar results. In both cases, there is an increase in memories from the 10-to-30 age period. Rubin and Schulkind (1997b) present similar results from twenty 73 -year-old subjects.

Hyland and Ackerman (1988) provide similar findings. Seventy-two individuals ranging from 17 to 73 years old were cued with object nouns, activity verbs, and feeling terms from Robinson (1976). Older volunteers showed a clear increase for memories from their teens and early twenties. In Figure 1, we plot the data from 12 volunteers with a mean age of 70 , the age group from the other two studies shown in Figure 1. Hyland and Ackerman did not exclude recent memories, but they reported that $47 \%$ of the 70 -year-old subjects' memories occurred within the subjects' most recent decade. In order to make their data comparable with those from the first two studies, we set the area under the first six decades of the Hyland and Ackerman data and the first two plots equal to each other. Adults in their sixties also showed a clear reminiscence effect. Adults in their fifties showed a possible reminiscence effect, whereas those in their forties had nearly equal numbers of memories from their teens, twenties, and thirties, with $80 \%$ of their reported memories falling within the most recent decade of life. For these adults, it is likely that any reminiscence effect was overshadowed by memories for recent events (Rubin \& Schulkind, 1997b).

Jansari and Parkin (1996) tested three groups of adults varying in age from 36 to 40,46 to 50 , and 56 to 60 . The adults were asked to provide autobiographical memories in response to presentation of each of Robinson's (1976) cue words. Half of the subjects were under normal instructions, and half had the added requirement that all memories had to be older than 2.5 years. Independent of these instructions, for reasons that are not clear, the data differ slightly from the other data sets in that they show fewer recent memories and more memories from childhood. Nonetheless, if the areas under the curves from both of Jansari and Parkin's conditions are equated, the two conditions show results similar to each other and to the other data sets. The data for the average of their two conditions for the oldest group are plotted in Figure 1, with the area under the curve up to age 50 set equal to that of Rubin et al.'s (1986) data set up to age 50.

Thus, from a collection of laboratories, there is a robust and substantial effect. When older adults are asked to provide autobiographical memories from their lives without restrictions on the content or time period, they show a marked increase in memories for events that have occurred in adolescence and early adulthood. The only way 


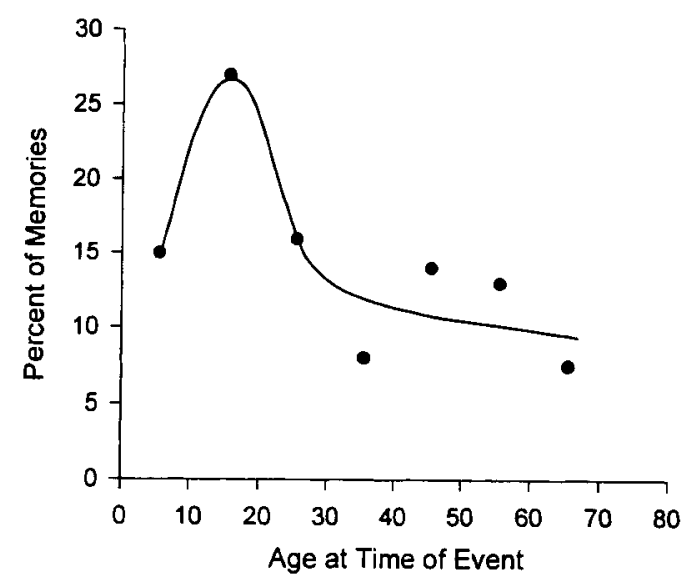

Figure 2. Distribution of vivid memories from older adults as a function of their reported age at the time of the event. Data from Fitzgerald (1988).

not to get this result seems to be to ask adults to recall events from individual thirds, quarters, or fifths of their lifespan for 5 or $10 \mathrm{~min}$ and see whether some periods evoke more memories than others (Howes \& Katz, 1992; Rabbit \& Winthorpe, 1988).

\section{Evidence for Enhanced Recall of Vivid Memories from Early Adulthood}

For people over 40 , there is a clear increase in autobiographical memories from early adulthood. The autobiographical memory task, however, is unlike most laboratory memory tasks, in that individuals recall any memories they choose rather than ones specified by the experimenter. Thus, the set of possible memories is much larger than in most laboratory tasks. The autobiographical memory task therefore can be seen as involving more sampling on the part of the subjects (Rubin, 1982; Rubin \& Wenzel, 1996). The number of possible memories that can be recalled can be reduced by specifying a subset of the memories. Several researchers have done this by requesting the recall of only the most vivid autobiographical memories. In addition to reducing the sampling problem, the request for vivid memories provides memories that, to the subject, are among those remembered best. Fitzgerald (1988) asked individuals with an average age of almost 70 and an average of 12 years of education to each report three "vivid" memories. As is shown in Figure 2, these vivid memories came disproportionately from early adulthood.

Two additional studies of vivid memories with older adults provide general support for Fitzgerald's views. Benson et al. (1992) have reported studies in which 10 vivid memories were requested from Japanese and rural Midwestern American volunteers. Both groups showed more of these vivid memories for early adulthood: the Japanese for ages 21-30 and the Americans for ages 11-20, the difference being due either to cultural factors or to the effects of the aftermath of World War II. Cohen and Faulkner (1988) requested 6 vivid memories from adults ranging from 20 to 87 . Unlike in the other studies, the older volunteers recalled the most memories from when they were 0 to 10 years old. If they had shown the common decrease for memories from the first decade, the results would be like those of the other studies in which vivid memories were requested. Independent of the discrepant point from the first decade of life, these results show a substantial retrieval from the early part of the peoples' lives.

Another observation should be made. In all of these studies of vivid memories in older adults, there is no increase for autobiographical memories from the most recent decades. Vivid autobiographical memories tend to come from the period for which we are claiming that events are remembered best.

In addition to these three studies of vivid autobiographical memories retrieved by older adults, there is a study in which adults of different ages were tested for their vivid memory of the same nominal event, the resignation of Prime Minister Margaret Thatcher (Cohen, Conway, \& Maylor, 1994). Consistent with the three findings just cited and the claim that memories from early adulthood are remembered best, Cohen et al. found that younger adults were more likely to form vivid memories of the event than older adults were.

\section{Preference for Events from Early Adulthood}

In addition to investigating memory, psychologists have also examined changes in the affective aspects of cognition. In several controlled studies, an increase has been found for judged importance and preference for events occurring during early adulthood.

Preference in cultural life. The first three empirical examples we will consider to support greater preference for experiences from early adulthood come from cultural activities: books, music, and film. One reason why books, music, and films from the 10 -to-30 period would be remembered better and judged more positively is that they are involved in one's initial understanding of these domains as an adult. Although children's versions of these art forms exist, they differ substantially as genres and are less likely to be retrieved later.

Figure 3 contains a distribution by decade of the ages at which 57 Danes, Norwegians, and Swedes with a mean age of 68 read a book of their own choice that provided a particularly memorable reading experience (S. F. Larsen, in press). The figure shows a peak for ages 10-40. Larsen notes that some parts of the distribution have simple explanations. The low value in the first decade may be due to a lack of reading ability. The high value in the sixties may be due to reading after retirement combined with less forgetting for recent books. The books from young adulthood, however, do not have such an obvious explanation, being from periods when people are often either reading assigned books in school or too busy to read as much for pleasure as they might later.

Holbrook and Schindler (1989) had 108 people ranging in age from 16 to 86 listen to 30 -sec excerpts from 28 


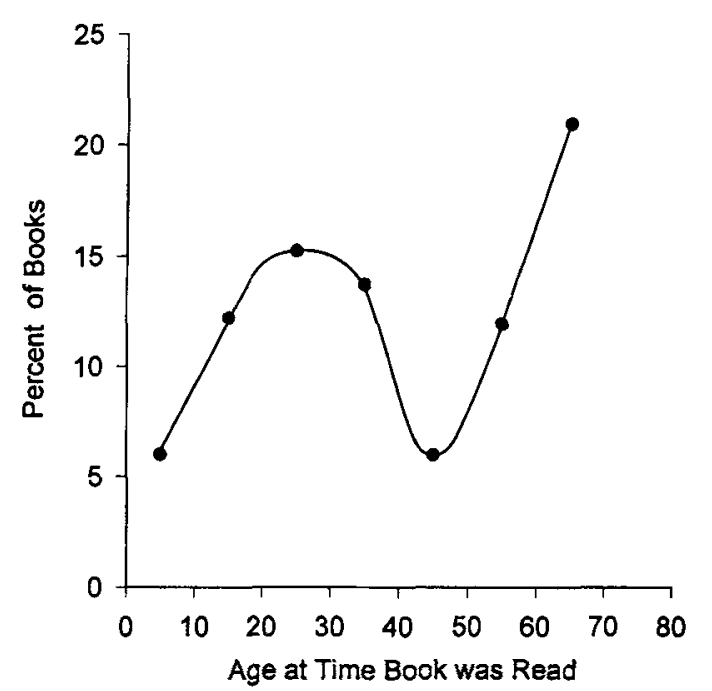

Figure 3. Distribution of particularly memorable reading experiences as a function of age at the time the book was read for a sample of older Scandinavian adults. Data from S. F. Larsen (in press).

songs popular between 1932 and 1986 . People rated each song on how much they liked it. Each person's ratings were converted to $z$ scores (i.e., $M=0, S D=1$ ), and the $z$ scores were summed to obtain a value for how much songs were liked as a function of the subject's age at the time the song was popular. Because the ages of the subjects varied continuously, different songs entered into the sums for each subject-age value. For instance, the Mills Brothers' 1952 hit "Glow Worm" would enter into the age 20 sum for someone born in 1932; Gene Chandler's 1962 hit "The Duke of Earl" would enter into the age 20 sum for someone born in 1942; and Peter Gabriel's 1986 hit "Sledgehammer" would enter into the age 20 sum for someone born in 1966. We have replotted their data in Figure 4 into decades from birth to 80 .

Holbrook (1993, p. 245) defined nostalgia as "a longing for the past, a yearning for yesterday, or a fondness for possessions and activities associated with days of yore." He measured nostalgia proneness, an increase in preferences for events and objects from early in the lifespan, with a series of 9-point-rating-scale questions such as "things used to be better in the good old days." In a study that is part of the literature on nostalgia in consumer research, Holbrook factor analyzed preferences of two groups of adults (mean ages 26 and 42) for the movies that won the Academy Award for the Best Picture between 1927 and 1988. He found that the year in which the film won the Academy Award (or alternatively to the ages of the judges at the time of the Award) was the largest predictor of preference (i.e., was the dimension with the highest eigenvalue). Nostalgia proneness was independent of the age of the subject, and it predicted different aspects of movie preferences than did age. However, if nostalgia proneness exists as a general tendency in most people, it should lead to an increase in the number of spaced retrievals from early adulthood.
There is another relevant study that uses films, which is included in this section though it is not really about preference. Sehulster (1996) had 89 residents of Connecticut between the ages of 26 and 67 perform a series of tasks including the following three: (1) They were asked to list at least five favorite films: ones that they would recommend as personal favorites or that would describe who they were. They were asked to include the age at which each film had become a personal favorite. (2) This question was a foil to help define the next question to the respondents: to list at least five films that defined or captured the theme of their era, films they would recommend to someone younger or older to better understand their age group. They were asked to include the age at which each film was seen. The films should have premiered during their era; they should not be later films about their era. (3) Finally, the respondents were asked to indicate when their era began and ended. The term era was purposely not defined for the respondents.

The mean span of the term era as indicated directly by the respondents was $15-25$ years. Their mean age at the time of their favorite films was 28 , outside their defined era, whereas their mean age at the time of their era-defining films was 22, inside their defined era. People responded that their era ended at 23 if they did not attend college and 26 if they did. No other questions were affected by education and none of the other factors investigated, including the age of the respondents, affected the reported beginning or end of the era. From this, Sehulster concluded that the age segregation of college with its increased rehearsal of shared events within an age-segregated group plays a role in the definition of what is termed here as early adulthood.

Judged importance in public life. Schuman and Scott $(1989$, p. 359) expand on the idea "that each generation receives a distinctive imprint from the social and political events of its youth." Proceeding from the work of Mannheim (1928/1952), Schuman (Schuman \& Rieger, 1992; Schuman, Rieger, \& Gaidys, 1994; Schuman \& Scott, 1989)

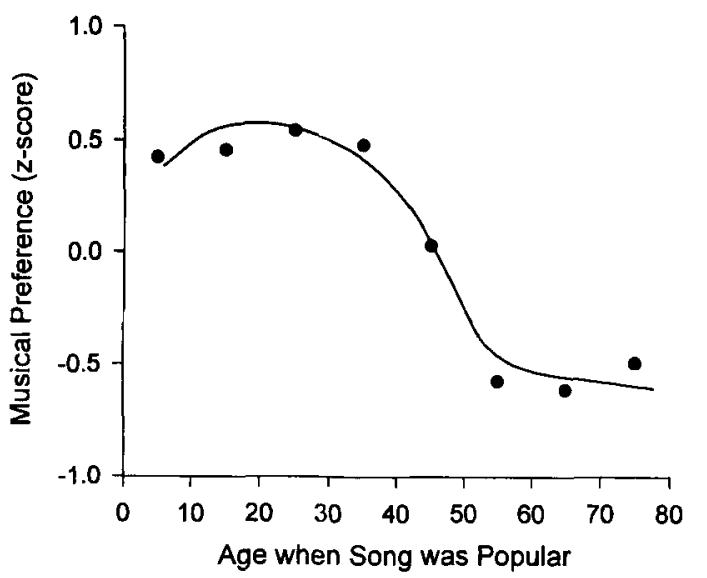

Figure 4. Distribution of $z$ scores of how much individuals ranging in age from 16 to 86 liked songs as a function of age when the song was popular. Data from Holbrook and Schindler (1989). 

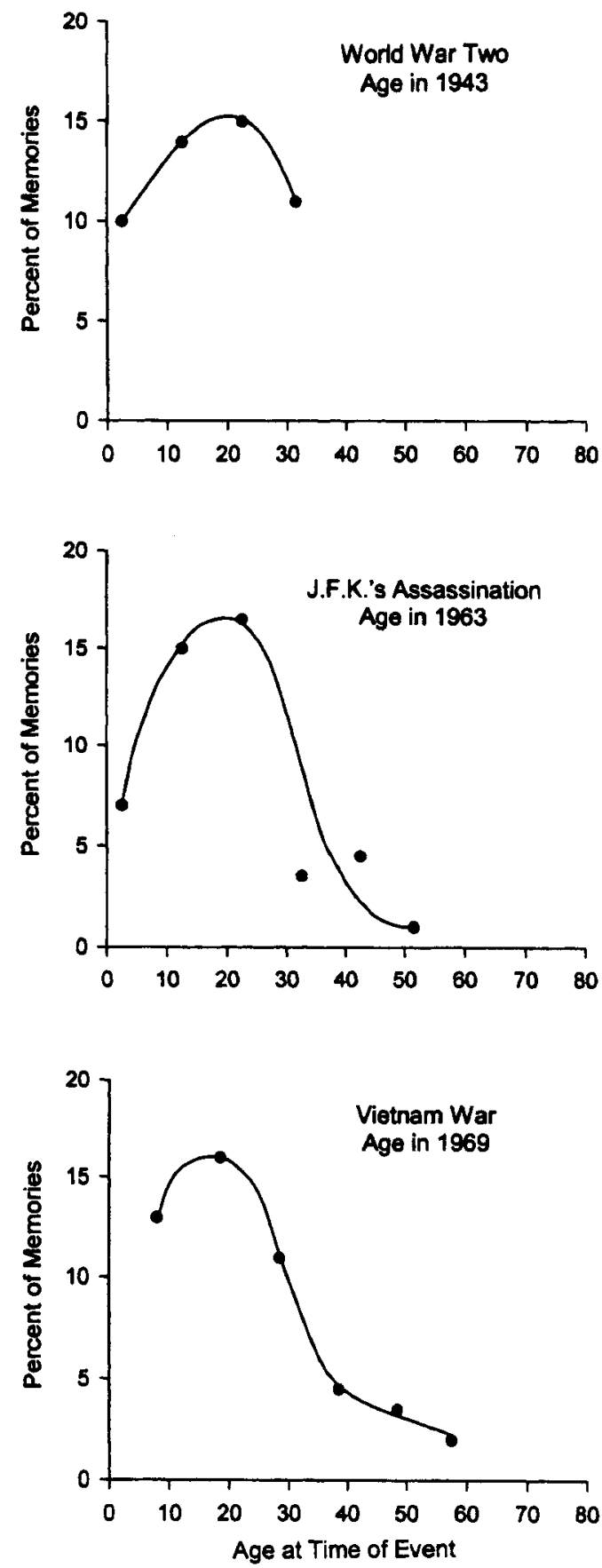

Figure 5. The top panel contains the distribution of the percentage of times World War II was reported as one or two of the most important public events of the past 50 years by adults from the United States, as a function of the age of the individual reporting the event in 1943, the middle of the war. The curve does not continue to age 80 , because none of the people sampled were over 35 at the time of the war. The middle panel contains the percentage of times John $F$. Kennedy's assassination was reported, as a function of the age of the individual reporting the event in 1963. The bottom panel contains the percentage of times the Vietnam War was reported, as a function of the age of the individual reporting the event in 1969 , the estimated middle of the war. All data from Schuman and Scott (1989). viewed generation as a social creation rather than a biological necessity, a creation that is usually formed between the ages of 17 and 25. For Schuman and Mannheim, the issue is not one of personal identity but political and social identity. Schuman views events coming from the 17-to-25 age range as crucial even though events from other periods also have effects (Stewart \& Healy, 1989). Each generation's political identity is shaped by the events that occur in its early adulthood and that it remembers best later in life (Conway, 1997). Moreover, Schuman postulates that cognitive factors are the mechanisms that produce the limited period of political identity formation. Before the age of young adulthood, people lack the cognitive abilities to learn about complex events, but even after they have acquired these abilities, in our culture they lack much awareness of the world beyond the family until age 17 . The frequently reported political events of adolescence and early adulthood are the first political events encountered and understood, and these events benefit from all the extra mnemonic benefits of first events, such as more effort after meaning and less proactive interference.

In 1985, Schuman and Scott (1989) asked a probability sample of 1,410 Americans over 18 to list one or two especially important "national or world events or changes" from the last 50 years. As sociologists interested in the concept of generation, they asked for public rather than personal events. Figure 5 presents the data from three of the most often listed events that had clear temporal boundaries: World War II, the assassination of John F. Kennedy, and the Vietnam War. The percentage of the total responses to each of these three events is plotted against the age of the person reporting that event at the time the event occurred. The ages are approximate because two of the events plotted had durations longer than a year. For these events and others, the peak time of the reported event occurred when the person choosing the event was in the teens or twenties. Any of the respondents could have responded with any (or none) of the events listed. The empirical observation is that people remember, and report as important, public events that happened in their late teens or early twenties.

Judged importance in personal life. If one wants to know when the personal events that people consider as most important occurred across their lifespans, one can simply ask. For instance, Fromholt and S. F. Larsen (1991, 1992) asked 30 Danes to spend $15 \mathrm{~min}$ recalling events that had been important in their lives. The volunteers were between the ages of 71 and 89 and had an average of 7 years of education. An-age-and-education-matched group of 30 Alzheimer's patients was also tested. Whereas nonAlzheimer's volunteers recalled an average of 18 memories, the Alzheimer's patients recalled only 8 . However, as the top panel of Figure 6 shows, the percentages of memories per decade of the Alzheimer's patients did not differ from those of the controls, except in the most recent decade. Both groups reported the most memories from early adulthood. The increase in memories from the most recent decade among the Alzheimer's patients was caused by mem- 
ories cued by the room in which the volunteers were tested. Thus, counter to what might be expected from loss in other forms of amnesia (Butters \& Cermak, 1986), there was no differential loss of recent memories noted in the Fromholt and Larsen study.
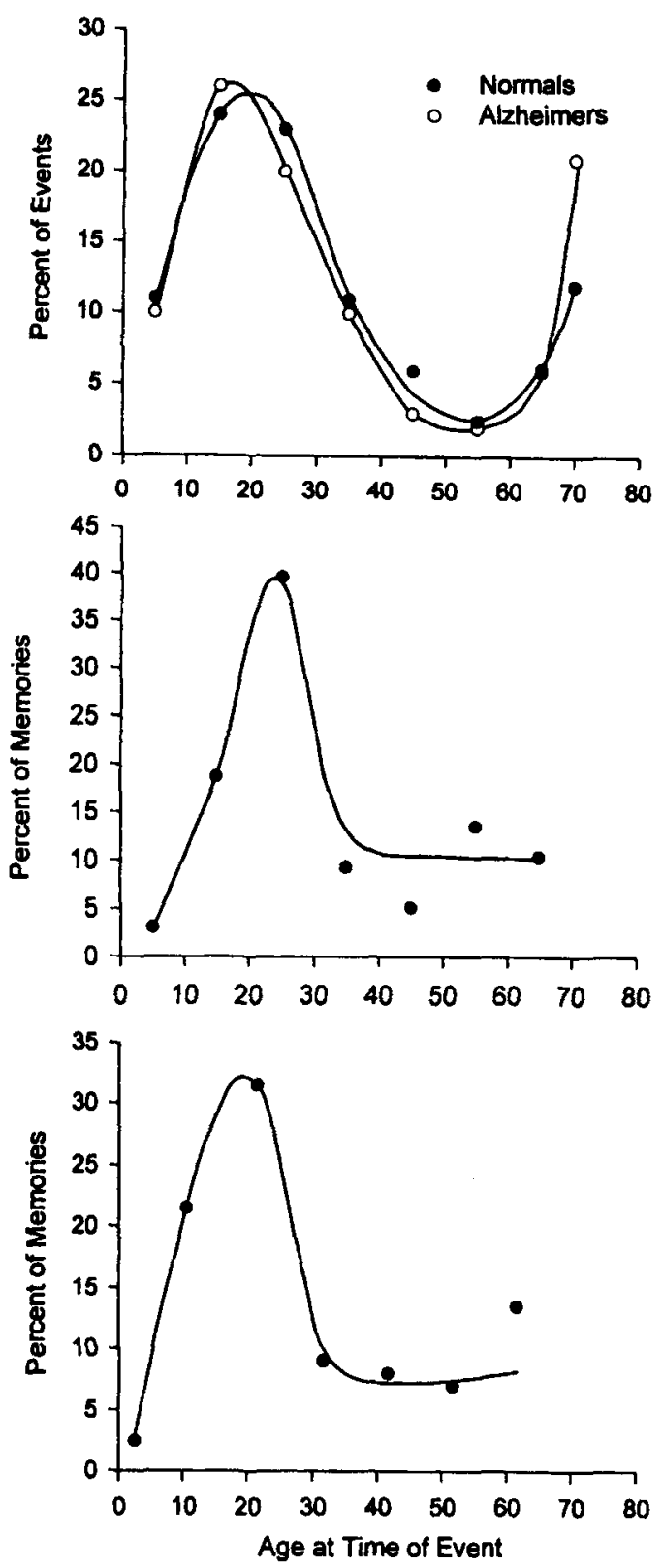

Figure 6. The top panel contains the distribution of events reported as personally important from older Danish adults as a function of reported age at the time of the event. Data from Frombolt and S. F. Larsen (1991). The middle panel contains the distribution of events reported as personally important from older Durham, NC residents as a function of the reported age at the time of the event. Data from Rubin and Schulkind (1997b). The bottom panel contains the distribution of events chosen by older adults to be among the four to go into a book about their lives as a function of the reported age at the time of the event. Data from Fitzgerald (1996).
Fromholt, P. Larsen, and S. F. Larsen (1995) found that patients suffering from their first major depression showed a pattern similar to the one in Figure 6, except that the depressed patients had more memories from the most recent years at the expense of memories from their teens. This pattern persisted 6 months later, after the depression. Whereas the depressed patients' memories older than 5 years were judged to be emotionally positive, neutral, and negative as often as those of the controls, their recent memories were more negative. This increase in recent negative memories disappeared after 6 months. Thus, the older bump memories were more resistant to the emotional changes of the major depression.

Rubin and Schulkind (1997b) had sixty 70- and 73year-old Durham residents record the five most important events of their lives and then date them. Their average level of education was 16 years. The distribution of important memories is shown in the middle panel of Figure 6. Again there is a peak in early adulthood.

Fitzgerald (1996) asked 45 adults between the ages of 31 and 46 as well as 60 adults between the ages of 60 and 76 for four memories they would want included in a book about their lives. If one views the self as the narrative of one's life, then such data are the clearest plot of what aspects of life lead to identity. Both groups showed a similar pattern. The distribution for the older group is shown in the bottom panel of Figure 6.

Fromholt and S. F. Larsen's $(1991,1992)$ peak for important memories was in the 11-to-20 decade. Fitzgerald's (1996) distribution of book memories for older adults peaked at 16 to 25 . Rubin and Schulkind's (1997b) peak came in the 21-to-30 decade. The move toward higher ages for the peak follows the years of education of these three groups $(7,12$, and 16 years, respectively). This may reflect differences in life experiences that accompany increased education or, following Sehulster (1996), may reflect the effects of longer age segregation. But, apart from minor variations in the location of the peak, it is clear that in all three studies there is an increase in reporting of important memories from early adulthood.

Formal written autobiographies can also be searched for important events. Mackavey, Malley, and Stewart (1991) analyzed the chapter-long autobiographies of 49 eminent psychologists for what they termed autobiographically consequential experiences. Many of these experiences were of single episodes and were often of vivid or flashbulb quality. Most, however, extended over longer periods. Nonetheless, as shown in Figure 7, even for these carefully composed, well-contemplated intellectual autobiographies, events and experiences from early adulthood, and especially from the college years, were mentioned most often. As the authors note (Mackavey et al., 1991, p. 57), "The greatest concentration of memories for our subjects did not occur during the recent time of their lives, but rather some 50 or so years earlier." In addition, autobiographically consequential experiences from the period spanning ages 18 to 35 had approximately twice as many explicit reports of affect as did reports from surrounding periods. 


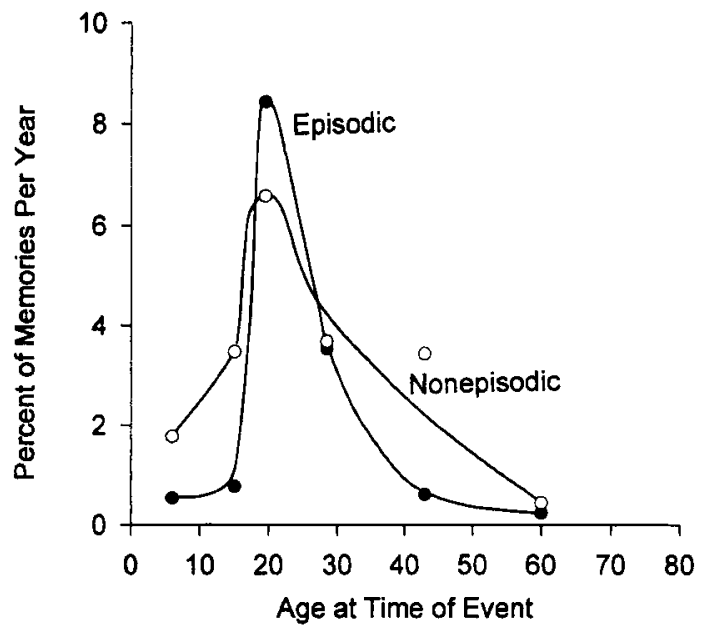

Figure 7. Distribution of autobiographically consequential experiences from the autobiographies of eminent psychologists as a function of the age at the time of the experience. Episodic and nonepisodic experiences are plotted separately. Data from Mackavey, Malley, and Stewart (1991).

\section{EXISTING QUESTIONNAIRE STUDIES OF PUBLIC EVENTS}

Given the evidence so far, one might expect an increase in memory for general knowledge that is encoded when a person is between 10 and 30 years old. However, the questionnaire literature that examines changes in memory for factual material learned over the lifespan provides no clear answers. The proper tests have not been made. We can, however, examine the existing literature for what evidence does exist. We will start with studies that have not found an increase in memory for events from early adulthood, often after one was explicitly expected. Then we will examine studies that on reanalysis do show an increase. Note that in these questionnaire studies there are several major changes from what has been reviewed so far. There is a change to verifiable, public knowledge that is often better classified as semantic as opposed to episodic memory. There is a change from items selected by the subject to items selected by the experimenter. The format usually changes from recall to multiple-choice recognition.

Longmore, Knight, and Longmore (1990) prepared a recognition questionnaire spanning six decades. They found no evidence for memory's being better for events encoded in early adulthood. In preparing the test, a brief description of each of 70 famous people was selected from over three times that number of people. In pilot work, the description of selected people had to be (1) correctly chosen by at least $50 \%$ of the adults over 40 who were more than 10 years old at the time the person was famous, (2) correctly chosen by less than $30 \%$ of the subjects who were younger than 10 at the time the person was famous, and (3) not correctly chosen much more often by respondents of one gender. These selection criteria are reasonable for most purposes and necessary if an optimum psychometric instrument to measure individual differences is to be pro- duced. However, the first criterion minimizes the chances of finding a decrease in the number of questions answered correctly from any time period. If an average of over $50 \%$ must be obtained for a question, there is less possibility of any age group's producing a low level of recognition. The last criterion may reduce the role of domain-specific knowledge of the type shown to have clear peaks in the section on preference. Given that two thirds of the original questions were rejected for not meeting the criteria, such selection procedures could easily remove any increase from the 10-to-30 period that was present in the initial set of questions. Howes and Katz (1988) used similar criterion to remove $38.5 \%$ of their initial questions and also failed to show a clear increase from the 10-to-30 period.

Warrington and Sanders (1971) made both recall and recognition questionnaires sampling both important news stories from a 40-year interval and the names of famous people shown in photographs from a 25 -year interval. They found that older adults recalled less than younger adults, but that there was no evidence that remote memories, including those from early adulthood, were recalled better than recent ones. No clear selection criteria for the questions were reported, and so, unlike for the Longmore et al. (1990) and the Howes and Katz (1988) studies, no clear criticism of the selection procedures can be made. However the lack of a fixed selection procedure or algorithm in these studies is a serious limitation on their being used here. If events from the early adulthood of the person selecting the questions are remembered best, the age of the person selecting the questions is important. Questions of seemingly equal difficulty for an experimenter of one age will not be equally difficult for a subject of another age. Thus, if we are correct, experimenters will choose objectively harder questions for events that occurred from when they were between 10 and 30 years old because they seem easier to them. A decision made by an experimenter of one age or several experimenters of different ages or a decision that removes items not known by subjects of certain ages could easily lead to a questionnaire that produced no effect of age.

There are studies that show an increase from the 10-to-30 period, but they are subject to many of the same methodological problems as are the studies that do not show the increase, though not the one of having a formal selection from among a larger set of questions that is based on subject performance. Consider the results from Meudell, Northen, Snowden, and Neary (1980). Patients with alcoholic amnesia and controls, both with mean ages of approximately 60 , tried to recall the names of voices played to them. They were then cued by four pictures, one of which went with the voice, and they were again asked the name. Finally they were asked to recognize the name by choosing it from among four alternatives while the voices were being played. Figure 8 shows the data from the control subjects. The controls (as well as the amnesics) showed a clear increase for names from when they were 25 on all three memory measures, and, as expected, the amnesics recalled less, especially from the most recent decades. The between-group comparisons, which were the purpose of 


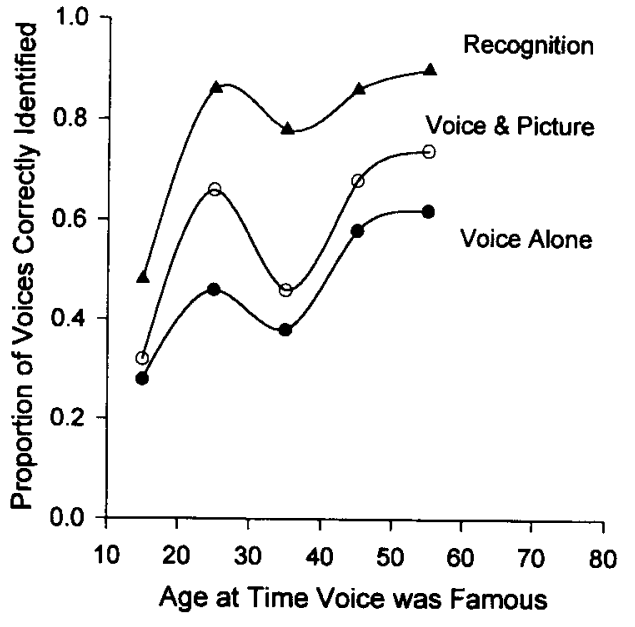

Figure 8. Memory of control subjects for famous voices as measured by identifying the voice alone (recall), from the voice and a set of four possible pictures (cued recall), or from the voice and a set of four possible names (recognition) (Data from Meudell, Northen, Snowden, \& Neary, 1980).

the study, are fine. However, for our purposes, the results are ambiguous. The increase at the age 25 decade could either have occurred because the subjects remembered more from when they were young adults or because the questions for that period were easier. Similar results occur with Marslen-Wilson and Teuber (1975). Their use of two age groups allows the effects of enhanced memory from early adulthood and the effects of the particular questions to be tentatively isolated, and it appears that most of the increase for young adulthood is due to the questions.

Botwinick and Storandt (Botwinick \& Storandt, 1974, 1980; Storandt, Grant, \& Gordon, 1978) performed a series of experiments in which they used variants of the same questionnaires. For each decade, there were two questionnaires which tested recall, one of current events and the other of entertainment; each comprised three questions per decade. In the first study (Botwinick \& Storandt, 1974), only the current events questionnaire was used, and questions were grouped by 20 -year periods instead of decades. Botwinick and Storandt tested 20 adults in each of the six decade age groupings from people in their twenties to people in their seventies and found an increase in recall of memories from youth. Because of the limited number of questions per period, their plots are noisy. To average over the effects of questions, we used data from all six age groups and computed an average recall score for events that had occurred around the time when the person answering was $5,15,25,35,45,55$, or 65 . Thus, as in the Holbrook and Schindler (1989) study of popular music reviewed earlier, different questions and different people entered into each value. This measure is not perfect, in that there are more data for the earlier decades of life because more people had reached those ages. The values for the oldest decades are therefore less reliable in theory and in fact are harder to fit to a smooth curve. The results of this analysis constitute the upper curve in Figure 9.

Storandt et al. (1978) used the same procedures but included both the current events and the entertainment questionnaires, centered on ages $0,10,20 \ldots$ rather than 5,15 , 25 ... Botwinick and Storandt (1980) used the same questions and procedures. Because there were approximately equal numbers of questions answered for each of the reported data points in the 1978 and 1980 studies, we averaged across the studies, equally weighting each of the originally published data points. The results of the combined 1978 and 1980 studies for the entertainment questionnaires constitute the middle curve of Figure 9. The current events questionnaires are shown in the lower curve of Figure 9. Combined, our analysis of an extensive and carefully conducted set of studies totaling over 450 individuals offers support for the claim that events from young adulthood are remembered best, though the original authors, examining the uncombined studies, found statistical support that memories from youth were remembered better for only two of their three administrations of the entertainment questionnaire.

The strongest existing questionnaire evidence comes from studies by Schuman, Belli, and Bischoping (1997) and Belli, Schuman, and Jackson (1997). Inserted into a longer survey interview were questions asking that a subset of the following events or people be identified: the WPA, the Holocaust, the Marshall Plan, Joe McCarthy, Rosa Parks, the Tet Offensive, the Village of Mylai, Woodstock, John Dean, Watergate, and Christa McAuliffe. At least 1,000 adults answered each question. People were most often accurate when the event queried came from their transition from childhood to adulthood. Moreover, errors often occurred because a question about an event or per-

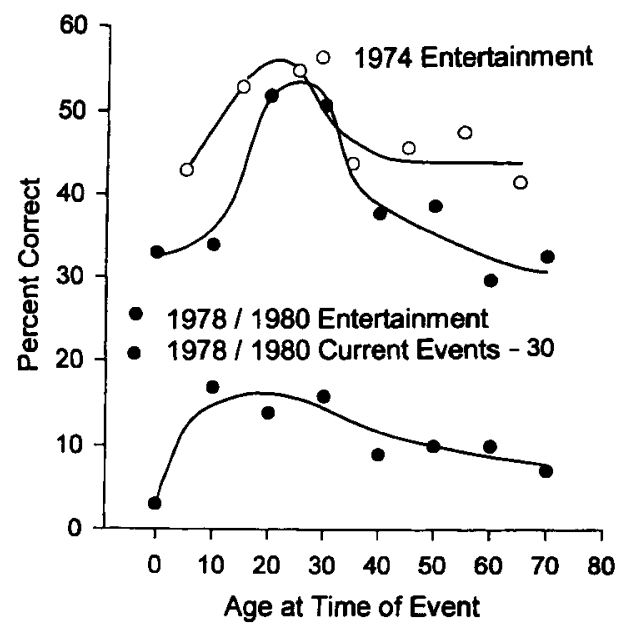

Figure 9. Percent recalled by adults between the ages of 20 and 80 on entertainment and current events questionnaires. Data from Botwinick and Storandt (1974) and from the combination of Botwinick and Storandt (1980) with Storandt, Grant, and Gordon (1978). 
son outside this transition period was answered as if it had come from the transition period. For example, 18 people reported that the Tet Offensive came from the Korean War. The modal age of these people during the Korean War was 24 to 33; they were 40 to 49 during the Vietnam War. Such apparently schema-driven errors are consistent with the account put forth here and with Belli et al.'s claim that our understanding of the political world forms in early adulthood and is used to understand and remember, but that it also exerts proactive interference on the recall of later events.

\section{A NEW QUESTIONNAIRE STUDY}

A questionnaire was assembled and administered that provides a direct test of the claim that events from early adulthood are remembered best. Here we are not testing the relative frequency of recall of autobiographical memory or preference, but the multiple-choice recognition of semantic, general knowledge of material learned at different periods of life. Keeping in mind the earlier attempts and the criticism offered of them, we took the following five steps. First, we included questions that were chosen in a mechanical or algorithmic fashion to have nominally equal difficulty. Second, we made questionnaires for three different knowledge domains, in order to ensure that our results would not be limited to one area. Third, although we usually included questions for every year, we averaged across years in order to provide a value for each decade and to exclude the possibility that a few especially easy or hard questions would have a major impact on our results. That is, although all our questions about what teams played in the World Series or what movie won the Academy Award are of nominally equal difficulty, some years are just more important, interesting, or memorable than others, and averaging over years minimizes such effects. Fourth, we administered the questionnaire to two different groups of older adults at two different times separated by a decade so that we could further average over particular questions. That is, we tested people who were the same age in different years to separate cohort and question effects from our age-at-the-time-the-event-occurred measure. Fifth, we administered the questionnaire to two different groups of undergraduates at two different times separated by a decade. If events from some decade had become a part of our general culture and therefore were generally known and rehearsed by people of all ages, such events would be easier for undergraduates who did not experience them as well as for the older adults who did.

\footnotetext{
Method

Materials. Five different sets of five-alternative multiple-choice questions were formed, each according to a different algorithm in order to ensure that all questions were nominally of equal difficulty: World Series, best picture, best actor or actress, most important current event, and losing presidential candidate. A listing of the most important 10 news stories was obtained from the Associated Press Standard reference works were used to formulate each of the other domains in 1984 and again to update them in 1994. Separate booklets were formed for each of these five domains. The five domains were collapsed into three topics for the analysis presented here
}

World Series, Academy Awards, and current events. The reduced set of three scales was used because of the similarity of the two film questions and the fact that there were fewer presidential questions because presidential elections in the United States occur once every 4 years. We limited our work to five sets because we could not find any other domains that spanned close to 70 years and had questions that could be generated in a fairly mechanical way.

The World Series questions provide a clear example of generating questions by algorithms. For each year, the correct choice was the baseball team ranked first in the American League versus the team ranked first in the National League. There were four foils for each year. One foil consisted of pairing the teams ranked in second place in each league and another foil consisted of pairing the teams ranked last in each league. Two other foils were made by pairing teams between second and last place. For years in which there were eight teams in a league, fourth and sixth place were used, and these changed proportionally as each league expanded to include more than eight teams. If any of the pairs of teams selected to be foils actually participated against each other in a World Series within 5 years of the target date, a substitute for that pair was made by choosing one team with the next lowest ranking. If this did not work, a team with the next highest ranking was used, then a team two below, two above, and so forth. In this procedure, we treated franchises that had moved, such as the errant Boston-Milwaukee-Atlanta Braves, as different teams. The application of the rules was mechanical, with choices among any arbitrary alternatives that might occur made by the flip of a coin.

For the questions about which movie won the Academy Award for best picture in a given year, we used nominees who lost for all four foils. One was a nominee from that year, and the remaining nominees were from $\pm 1, \pm 5$, and \pm 10 years away from the target year. The plus or minus direction was chosen randomly. Care was taken not to use nominees as foils more than once. If a choice for a foil had already been used, the plus/minus direction was reversed. If there was still no foil available, the choice was one year further and then one year closer.

The questions about the best actor or actress followed the same basic procedure as that for the best picture, but this procedure was more complex because the same person could be nominated and could win during more than one year. Either an actor or an actress question was made for each year and the foils were always of the same sex as the correct actor or actress. Neither the correct answer nor any foil could be a winner for any year within 5 years. (Both winners in 1937 and 1938 were excluded by this rule.) Within these constraints, an attempt was made to obtain five actor and five actress questions per decade.

For the question about what was the most important news story of the year, the correct answer was the number one Associated Press story of the year. The foils were all also from the Associated Press list of the most important 10 stories. The foils were the number two or three story from \pm 2 years, the number four or five story from \pm 4 years, the number six or seven story from \pm 6 years, and the number eight or nine story from \pm 8 years. We used foils only once, and we excluded events as foils if they extended over a period that included the critical year.

For the question about who was the Republican or Democratic candidate who lost the presidential election, the foils were (1) the Vice-Presidential candidate from the same party as that of the correct answer, (2) a randomly chosen two-or-more-term senator from the same party as that of the correct answer, (3) a randomly chosen first-term senator who did not get re-elected from the party of the winning presidential candidate, and (4) a name created by randomly choosing first and last names from two different first-term senators who were not re-elected. No politicians were used as foils who later became major-party presidential or vice-presidential candidates.

For the five domains described, questionnaires were formed by using algorithms to produce questions of nominally equal difficulty. There were 89 questions for the World Series, 66 for the best film, 
64 for the best actor or actress, 57 for the news stories, and 24 for the presidential elections. Thus, the questions were formed without judgments by experimenters or pilot testing of subjects to balance the difficulty of the questions. Each question had one correct answer and four foils that were graded in difficulty. For the World Series and presidential questions, the difficulty was in terms of similarity to the correct answer. For the film and current event questions, the difficulty was in terms of both similarity and temporal judgment. Each of the five sets of questions was typed into booklets in chronological order, starting with 1900 for the presidential questions and the earliest year available for the other questions (1905 for the World Series, 1928 for the Academy Awards, and 1937 for the news stories). The last year for each questionnaire was the year before testing (1983 or 1993). For the 70 -year-old subjects tested in 1984, there were presidential and World Series questions starting at their birth. The Academy Award questions started with the time when the subjects were 15 and the news stories from the time when they were 24 . For the 70-year-old subjects tested in 1994, the Academy Award questions started with the time when the subjects were 5 and the news stories from the time when they were 14 . A decrease in accuracy for the first 10 to 15 years of life was not our main concern, because that was predicted by most theories and existing questionnaire studies. The main absence of data occurred for the 15-to-24 year period among the older adults tested on current events in 1984, because no questions were available for those years for these subjects.

Subjects. Sixty adults were tested in 1984: 30 Duke University undergraduate students who received credit toward a course requirement (mean age $=21.1$, range 18-22; mean years of education $=$ 13.9 , range 12-16), and 30 older adults who were recruited from the laboratory pool of the Mental Performance and Aging Laboratory at the Boston Veteran's Administration Hospital (mean age $=69.7$, range 68-72; mean years of education $=13.3$, range 9-18). Sixty adults were tested in 1994: 30 Duke University undergraduate students who received credit toward a course requirement (mean age $=19.2$, range 18-22; mean years of education $=13.6$, range $12-15$ ), and 30 older adults who were recruited from the Duke Center of Aging and Development and were paid $\$ 5.00$ for their participation (mean age $=$ 69.8 , range 66-72; mean years of education $=16.5$, range $12-22$ ).

Procedure. Subjects were tested in either 1984 or 1994 and were tested in small groups. Each person was given a questionnaire packet which consisted of several questionnaires. They were instructed to answer the questions as quickly as possible. The subjects were informed that because of the nature of the information requested, no one would be likely to be able to answer all of the questions accurately, and that they should therefore guess if necessary. The order of the questionnaires was counterbalanced to ensure the absence of fatigue effects. The subjects were given as much time as they needed to complete the questionnaire packet, and they usually finished within $2 \mathrm{~h}$.

\section{Results}

Data were grouped by the average age of the subject's group at the time of testing, regardless of the year of the test. Questions were combined so that each subject in the 1994 testing produced 21 percentage correct values: one for each of seven decades for each of the three scales (World Series, Academy Awards, and current events). The subjects in the 1984 testing produced 20 percentage correct values because there were no Academy Award questions for their 0 -to-10 decade. Percentages were used because the number of questions in each scale for each decade varied. For instance, because presidential elections in the United States are held every 4 years, for the current-events scale some decades were based on 10 news story questions and 2 presidential questions; other decades were based on 10 news story questions and 3 presidential questions; and still others, from the years before 1937, when the Associated Press first listed the top 10 news stories of the year, were based only on presidential questions. Our basic principle was to have each question answered count equally in its decade score.

Performance of the older adults on the three domains is shown in Figure 10. The $x$-axis denotes the age of the subjects at the event described in the questions. The $y$-axis denotes the mean percentage correct responses. Because each question had 5 possible answers, the $y$-axis begins at the one-in-five, or $20 \%$ chance, responding level. Each point on the graph represents the mean percentage correct responses made across 10-year periods and is placed at the midpoint of each 10-year decade (e.g., 15 for the 11-to-20 decade). As can be noted from the figure, older subjects were generally more accurate at responding on questions derived from the decades in which they were 11 to 30 than on questions for any other decade, except, possibly, the most current decade of their lives. This observation is obvious for the entertainment questionnaire and the current events questionnaire, but not for the baseball questionnaire.

A combined measure for all questionnaires was also made by using a formula based on the average number of questions in each questionnaire: (20 - Academy Awards + 12.5 current events $+10 \cdot$ World Series $/ 42.5$. Values for this measure for the older adults are shown in the top panel of Figure 11. The younger subjects' results are shown in the bottom panel, to ensure that the questions behave in a reasonable fashion. Age-at-the-time-of-the-event values for the younger subjects are negative for most decades, because these subjects were not yet born at the time of most of the events about which they were questioned. As can be noted from the figures, the younger subjects demonstrate typical forgetting, in that the farther from the present the time to which the question referred, the poorer the performance, although here, in a novel addition to the literature, we have preconception retention functions that reflect the loss of cultural knowledge over time. The forgetting pattern was obtained for every questionnaire and, consequently, for the mean of all questionnaires. Younger adults do not show any evidence of increased performance on the questions for the decades in which older adults were 11 to 30 . Thus, any bump observed in older adults is not due to questions for that decade being easier for subjects of any age.

The critical question is whether the older subjects performed better on questions coming from the period in which they were 10 to 30 years old. Four one-way ANOVAs were conducted in order to examine correct responding for the combined score for the three individual scales shown in Figure 10 and for the combined score shown in the top panel of Figure 11. Each compared the accuracy in responding on questions for the two decades from 11 to 30 with that on questions for the following two decades. Although the two surrounding decades (i.e., 0 to 10 and 31 to 40) seemed to provide a more natural comparison than did the two following decades, we used the two following decades to avoid missing data from the 0 -to- 10 decade. 

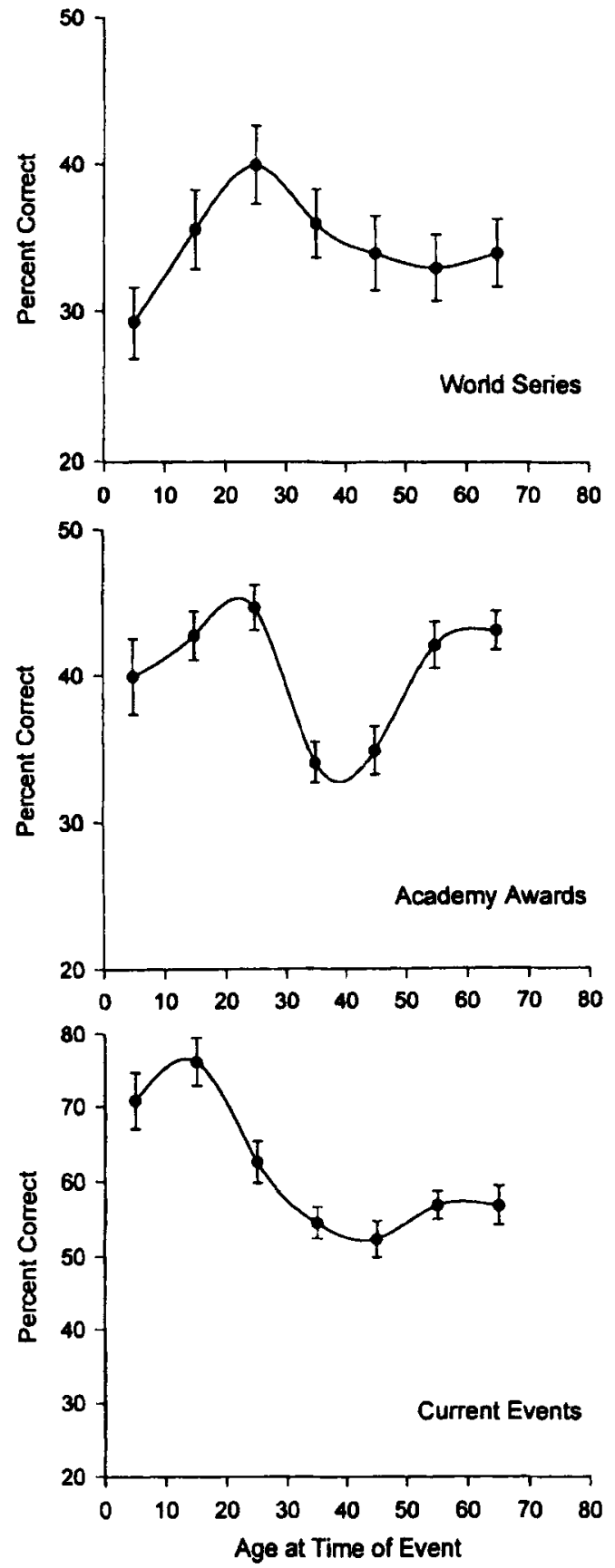

Figure 10. The percent of correct answers of the older subjects to five-alternative multiple-choice questionnaires (with standard errors) as a function of their age at the time of the event. The $y$ axis begins at the chance guessing level of $20 \%$. The current events score in the first decade is based only on the presidential questions.

Moreover, the measure used is more conservative in that a reasonable null hypothesis would not be of no difference, but one opposite to the direction that we predicted: people should recall more recent events (Rubin \& Wenzel, 1996). Thus, two scores were computed for each subject for each analysis. The first was the percentage of questions answered correctly for the years in which the subject was 11 to 30; the second was the percentage of questions answered correctly for the years in which the subject was 31 to 50 .

For the older adults for all questions combined, current events, and Academy Awards, the results were all significant $[F(1,59) \mathrm{s}=71.01,24.85$, and 40.60 , respectively]. For the World Series, they were not $[F(1,59)=1.79]$. The statistical tests are mirrored in the scores of the individual subjects as measured by the number of subjects whose score in the 11-to-30 period minus their score in the 31-to50 period was positive. For the all questions combined, current events, Academy Awards, and the World Series, $50,45,47$, and 31 subjects, out of a total of 60 possible subjects, had positive scores, where chance would be $60 / 2$ or 30 . For younger subjects, none of the difference were significant $[F(1,59) \mathrm{s}=1.99,2.62,1.05$, and 0.00 , respectively] and the numbers of subjects whose score in the 11to-30 period was greater than their score in the 31-to-50 period were $25,27,22$, and 27 , respectively. As a point of completeness, we note that all eight one-way ANOVAs for the combined and individual scales for the younger and older groups were significant, with $p$ s $<.0001$. Moreover, all results reported as significant for the combined 1984 and 1994 groups are significant if the 1984 or the 1994 testings are considered separately.

\section{FOUR MUTUALLY COMPATIBLE ACCOUNTS OF WHY THE BUMP OCCURS}

We have reviewed data that show the bump in the recall of autobiographical memory, the recall of vivid and important memories, and preference judgments. We have added new data that show the bump in the multiple-choice recognition of semantic memory. The interpretations of these findings rely on the theories used to explain them, and so we turn to four possible theoretical accounts of the bump from four different areas of psychology.

\section{A Cognitive Account}

The first account is based on standard principles of experimental psychology applied to a situation in which the environment is changing. Events from early adulthood may be remembered best because they occur during a period in which rapid change is giving way to relative stability. In times of rapid change, by definition, many novel events are encountered, but because of the rapid change, knowledge of such events is often of less value in future situations. Such novel events benefit from a host of memoryenhancing processes, including increased effort to understand the event, minimal proactive interference, and distinctiveness. However, there are also mnemonic costs to rapid change that occur mostly after encoding. These include a memory organization that is not the same at encoding as it is at retrieval, as well as less retrieval, and especially less spaced retrieval. Periods of stability produce the opposite effects. Encoding effort is smaller and proactive interference is larger; both effects produce poorer recall. However, the beneficial effects of a stable cognitive structure for cuing and spaced retrieval are increased. Thus, the best situation for memory is the beginning of a 

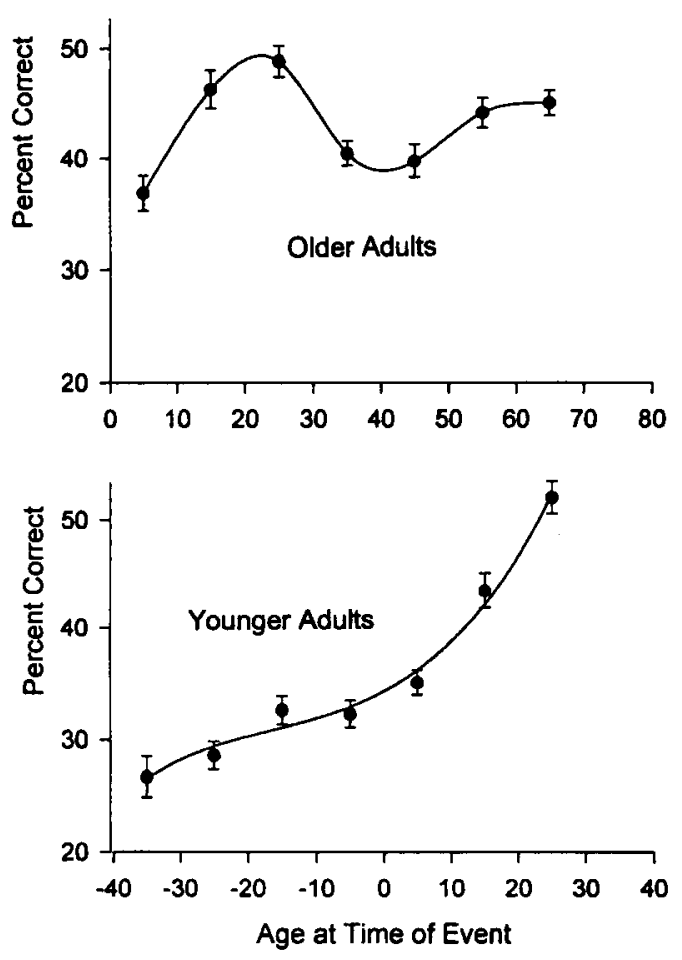

Figure 11. The percent of correct answers to a weighted combination of all the five-alternative multiple-choice questionnaires (with standard erors) as a function of their age at the time of the event. The $y$-axis begins at the chance guessing level of $20 \%$.

period of stability that lasts until retrieval. Events from such a period are still novel but are more likely to be retrieved later and thus will benefit from both memory-enhancing processes available during periods of change and periods of stability. Such events will be encoded well, retrieved regularly, and integrated into the stable cognitive structures being developed.

Thus, there are three main benefits of novelty on recall. First, when a novel event is encountered at the end of a period of change, there is more effort after meaning (Bartlett, 1932). By any theory in which time in working memory, schema formation, or any other explanation in terms of conscious effort to understand an event increases the event's memorability, such novel events would be remembered better (e.g., Atkinson \& Shiffrin, 1968; Craik \& Lockhart, 1972; Kintsch \& van Dijk, 1978). Second, there may be a lack of, or perhaps a release from, proactive interference, because the novel event is different from what has preceded it. Proactive interference is one of the most studied and most powerful causes of forgetting (Underwood, 1957; Wickens, 1970; see Rubin, 1995, for a brief review of this large literature). When one learns a series of similar items, one recalls later items with greater difficulty, but dissimilar items do not show this increased difficulty. In contrast to the effects of increased effort on encoding, similar events would be encoded but could not be recalled unless the interference was removed, such as by adding cues that would differentiate the event from those similar to it (Gardiner, Craik, \& Birtwistle, 1972; Rubin,
1995). Third, the first time that an event occurs, it should be more distinctive both because of its novelty and because more attention is paid to details that the individual will learn to ignore in later occurrences. Such distinctiveness is an aid to later memory (Hunt \& Einstein, 1981; Hunt \& McDaniel, 1993; Hunt \& Smith, 1996).

There are two main benefits of stability on later recall. First, events from stable periods are more likely to serve as prototypes or models for future occurrences and thus may be retrieved and rehearsed more as new events are retrospectively compared to them (Robinson, 1992). Because peoples' behavior repertoires first become stable during early adulthood, people at age 40 or 50 or 60 are more likely to retrieve knowledge acquired when they were 20 years old than knowledge acquired when they were 10 . Such a pattern of continued use, or spaced practice, is important for long-term retention (Anderson, 1990; Anderson \& Schooler, 1991; Bahrick, 1979; Bjork \& Bjork, 1992; Braun \& Rubin, in press; Dempster, 1988; Landauer \& Bjork, 1978). Second, once a stable cognitive structure has been established, this structure will serve as a stable organization to cue events. Such an organization is needed so that initially effective cues for an event can remain effective. When the cognitive organization changes or falls into disuse and is supplanted by a new organization, the old cues may no longer be effective. Moreover, in a stable environment, the cues present at encoding will be more likely to be present at retrieval. Such encoding specificity is an important factor in memory (Tulving \& Thomson, 1973).

These five benefits (three derived from novelty and two from stability) do not all come from the same integrated theory of memory and so cannot be claimed to be exhaustive or mutually exclusive. Nonetheless, this list represents principles that most cognitive psychologists would hold to be important for memory. The principles were not invented for the purpose of explaining enhanced memory at transitions, but combine easily to do so. One way to integrate these factors into a single framework is to note that items and events are easy to remember to the extent that the cues available at retrieval uniquely identify them from among all other items in memory (Hunt \& Smith, 1996; Rubin, 1995). This unique identification requires items that are both distinctive from other items and are also organized in a memory system that remains stable until retrieval. The more effort spent on understanding and encoding the items or events to be remembered because they are novel, the more likely such unique identifying cues will be formed. Such events will have high associative frequency (Rubin, 1983), availability (Tulving \& Pearlstone, 1966), or storage strength (Bjork \& Bjork, 1992). The more times the items are retrieved with long spacing because they are of continuing value, the more likely such unique identifying cues will be maintained at long delays. Such events will also have high current accessibility (Tulving \& Pearlstone, 1966), availability (Tversky \& Kahneman, 1973), or retrieval strength (Bjork \& Bjork, 1992).

The cognitive account can explain more than just enhanced memory. It is not a major leap to claim that for individuals, the events on which their understandings of the 


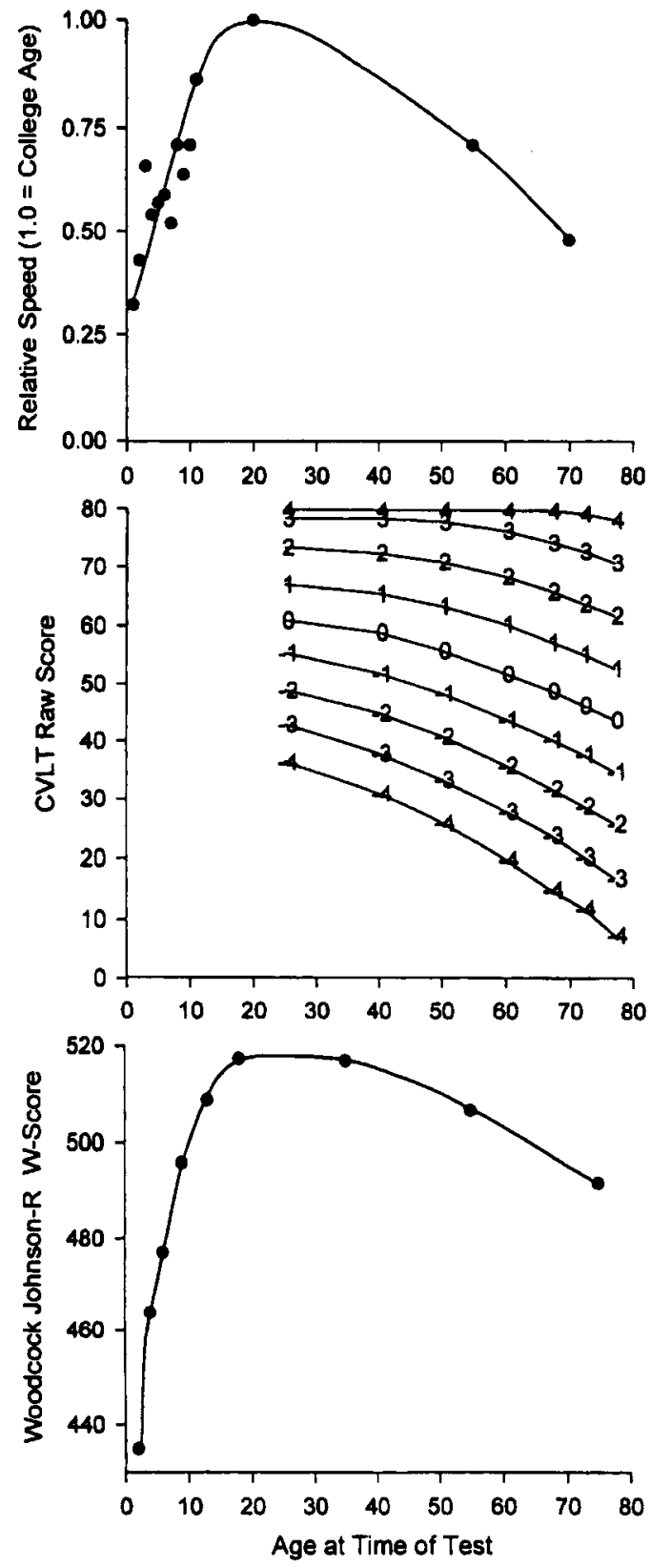

Figure 12. The top panel shows the factor by which the reaction times of people of different ages would have to be multiplied in order to approximate the reaction times of college students. The value of 1.00 at 20 years is set by definition. Data from Cerella and Hale (1994). The middle panel shows norms of the number of items correct needed for one to score at various numbers of standard deviations from the mean on the California Verbal Learning Test. The bottom panel shows norms of the number of items correct needed for one to score at a median level on the Woodcock-Johnson Revised Tests of Cognitive Abilities (Woodcock \& Johnson, 1991).

world are based will be judged more important than other events, or that such events will come to mind more easily when the recall of an important event is requested. Preference on the basis of familiarity and understanding is regularly observed (Moreland \& Zajonc, 1979; Zajonc, 1968; see Bornstein, 1989, and Zajonc, 1980, for reviews). Thus the cognitive framework in which one comes to understand the world helps determine which events will be viewed with positive affect and nostalgia; items or events that fit into familiar schemas are appreciated esthetically (Rubin, 1995).

The three remaining accounts lack specific mechanisms of the kind used by the cognitive account, but they can be viewed as acting through the cognitive mechanisms that we have just outlined.

\section{An Account Based on an Inflection in Cognitive Abilities or their Neural Substrates}

If cognitive abilities were to rise and fall as a function of age with the same time course as that for the bump, this rise and fall could account for the memory data reviewed here if one assumes that people learn in proportion to their ability. In contrast, if there was a rapid, major increase in abilities followed by a period of relative stability, or slow decline, then a more complex explanation would be needed. The latter pattern will be shown to be the case, first for cognitive processing speed, then for memory, and finally for fluid intelligence. Thus, we show that the rise and fall of cognitive abilities taken alone is insufficient to explain the bump. The observed pattern could account for the bump, however, if there was a more complex, nonlinear, relation between abilities and amount learned or if the cognitive account was used to supplement the cognitive abilities account.

There is abundant evidence of a slowing of cognitive processes in aging. Moreover, it can be argued that the slowing is a general index of and perhaps the cause of other cognitive deficits (Cerella, 1985, 1991; Cerella \& Hale, 1994; Cerella, Poon, \& Williams, 1980; Hale \& Myerson, 1995; Noble, Baker, \& Jones, 1964; Salthouse, 1991, 1994a, 1994b, 1996). Cerella \& Hale (1994) reviewed studies from the cognitive development and aging literatures in which reaction time tasks were used. The top panel of Figure 12 (based on their Figure 2, panel 2) reports their results in terms of the relative response speed (the reciprocal of reaction time), where the speed of 20-year-old subjects is set to 1.00 . This figure and other figures like it reviewed in Cerella and Hale support the idea of an inflection point in cognitive abilities at about age 20 .

Standardized tests offer another source of data on variations in cognitive abilities over the lifespan because the norms can be used to compare performance at various ages. For example, the middle panel of Figure 12 shows the number of items one needs to get correct to be average, or to be one, two, or three standard deviations above or below average for the California Verbal Learning Test. This test consists of paired-associate tasks similar to those used in the laboratory and so provides a close approximation to such laboratory work. In general, if one assumes that infants would do very poorly and young children not much better, this curve resembles those for response speed, with a rapid rise to about age 20 followed by slow decline. If the norms of the Wechsler Memory Scale (Wechsler, 1987), which combines a variety of working memory and longterm memory tests, were plotted in the same way, they would produce a similar figure. 
We also include a test of general intelligence in the bottom panel of Figure 12, though any of a host of more specific abilities could be pursued, as Ribot (1906) did for imagination. The Woodcock-Johnson: Tests of Cognitive Ability (Woodcock \& Johnson, 1991) score for Broad Cognitive Ability comprises broad areas such as memory, spatial relations, processing speed, and concept formation. Using Rasch ability scales (Rasch, 1960) items were scaled to determine their relative difficulty. In this way a continuous scale was developed that could be administered to people ranging in age from 3 to 80 . Following the values reported in the manual, we plot $W$ scores, which are an interval scale with a mean of 500 set to the performance of a beginning fifth-grade student. Thus, for this figure, there is no absolute zero.

In summary, laboratory tests of processing speed and standardized tests of memory and intelligence support the basic claim of a rapid increase in cognitive abilities of several kinds until early adulthood followed by a slower decline. Similar possibilities could exist at the neural level. An aspect of neural development could either follow a course similar to the cognitive abilities reviewed, with a rapid rise and slow decline, or it could peak sharply in early adulthood. Although most brain structures remain stable until fairly late in life, the number of large neurons in the cortex begins to decline earlier (Henderson, Tomlinson, \& Gibson, 1980; Terry, DeTeresa, \& Hansen, 1987), as does the proportion of gray matter (Jernigan, Press, \& Hesselink, 1990). It also could be that the neural basis of memories encoded in early adulthood are better. For example, in various forms of organic amnesia, memories for events from early adulthood are often spared (Ribot, 1882), and in Korsakoff's syndrome in particular (Butters \& Cermak, 1986), the long retrograde amnesia tends to last back to early adulthood. Moreover, it may be no accident that claims that people have a permastore memory (Bahrick, 1984) are all based on materials learned in early adulthood.

\section{An Account Based on Identity Formation}

According to Erickson (1950), a sense of identity develops in late adolescence. A major goal of this time period is to discover who and what you are socially, vocationally, and ideologically, and to merge these factors into an adult identity. Identity formation could provide an added motivation for using the cognitive mechanisms outlined. For instance, if identity is viewed as a narrative of the important aspects of one's life (Fitzgerald, 1988; Gergen \& Gergen, 1983; Robinson, 1996) and if much of identity is formed in early adulthood, there will be more events in that narrative that come from early adulthood than would be expected from a monotonic forgetting function. In addition, events from this period will be more likely to be organized and incorporated into an overall story or view of the self and thus benefit mnemonically from all the advantages of such a schematic organization as well as from increased spaced rehearsal. Similar effects would also occur if identity were viewed more like semantic memory than as a collection of episodic instances and if identity were at the cultural level of the concept of generation rather than at the personal level.

Another way to provide mechanisms for identity formation can be found in social contact theory. People tend to have more and varied social contacts in early adulthood than in early childhood or old age. To account for this observation, social contact theory has amassed a variety of evidence for the lifespan changes in three motives (Carstensen, 1992, 1995; Fredrickson \& Carstensen, 1990). Two motives were needed that peaked early in the lifespan: selfconcept development and maintenance and information seeking. Both result in the building of stable cognitive structures. The first focuses on self schemas of the kind used in identity formation, the second on schemas for the environment of the kind used in the cognitive account. In contrast to the account based on an inflection in cognitive abilities, the theory is social and environmental, not biological or maturational; the three motives change to match beliefs about the way in which one's life is going to change and when it is going to end. For instance, asking younger adults to imagine that they will be moving across the country in a few weeks makes their choice of with whom they would like to spend time more like the choices of older adults, and asking older adults to imagine that a new drug has been developed that would extend their life by 20 years makes their choice of with whom they would like to spend time more like those of younger adults.

\section{An Account Based on Genetic Fitness}

The cognitive mechanisms outlined here, the occurrence of identity formation in early adulthood, the society that fosters changes in early adulthood, and our increased cognitive abilities and brain function during early adulthood, could all be in the service of increased genetic fitness. As with many Darwinian explanations, this final alternative offers no obvious direct physiological or behavioral mechanism to test but can be seen as underlying the other forms of evidence discussed. As with the other alternatives, little in the way of detailed analysis will be offered, but rather enough data and theory are given to demonstrate that Darwinian arguments could be of value (cf. Bruce, 1985). Early adulthood could be special because it is the time of greatest fecundity, of the greatest potential to reproduce. That is, the increase in memory during the bump could serve the cognitive functions needed in selecting the best mate. The increase in preference could serve our developing loyalties to our offspring. We could be an organism that sacrifices an overall high level of functioning into old age in order to get a slightly greater advantage when it is needed to increase genetic fitness. In addition, it might not have been as common for our ancestors to live as long as we now do, so there might have been little selection pressure for a high level of functioning beyond a certain age.

Figure 13 is a plot of the number of births per 1,000 wives as a function of the age of the wife (Menken, Trussell, \& U. Larsen, 1986). In order to obtain an estimate of potential fertility, historical data from traditional societies 


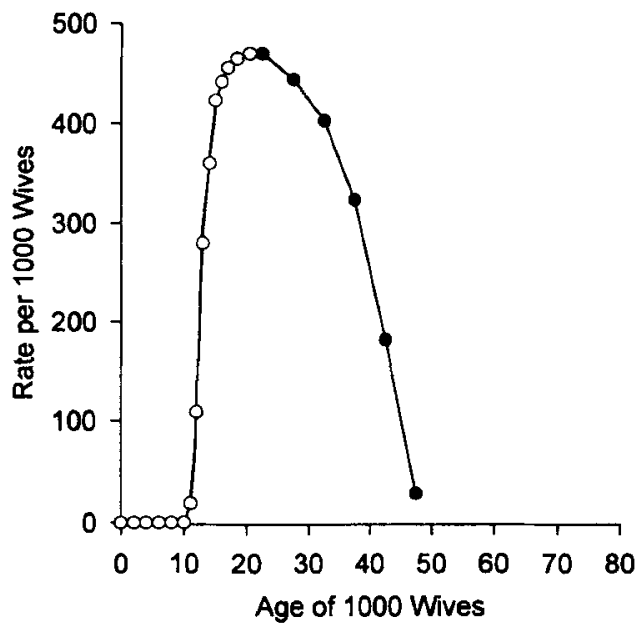

Figure 13. The solid circles are births per 1,000 wives in traditional societies as a function of the age of the wife. Data from Menken, Trussell, and U. Larsen (1986). The open circles are hypothetical values based on the percentage of women reaching menarche. Data from Komura, Miyake, Chen, Tanizawa, and Yoshikawa (1992).

without access to modern contraceptive techniques were used (e.g., marriages between 1750 and 1899 from German village genealogies, or data from the 1911 census in Scotland and Ireland). To provide points from before the age of 20, we used the proportion of women who reached menarche as a function of their age (Komura, Miyake, Chen, Tanizawa, \& Yoshikawa, 1992). To transform these proportions to values that can be put on the same scale as the fertility data, we multiplied each proportion by the number of births per 1,000 wives from the 20 -year-old period. The shape of the curve here is much closer to that of the memory data than were the cognitive abilities curves.

Slightly more subtle analyses are possible. The data for couples hide the difference between men and women. If the mechanisms discussed in earlier sections are motivated by genetic fitness, one might expect them to decline more rapidly for women (Menken et al., 1986), and to the extent that they have been measured, they do not. In addition, instead of asking how increased cognitive abilities might favor fitness during early adulthood, one could ask what survival value recalling memories from early adulthood later in life might have for oneself and one's offspring. Mergler and Goldstein (1983) have speculated that one role older adults serve in society is to maintain information that is not available to younger adults, information that comes from the older adult's early adulthood. If a situation arises that has not occurred in the lifetime of the younger members of a family, older members who could recall that information could be of help. They predicted, but in 1983 could not find in the psychology literature, evidence for "preferential access of very old memory material" (p. 80), evidence that is provided here for both autobiographical memory and factual material.

\section{SUMMARY}

If we are to build an integrated psychology by using natural science (Kimble, 1996), we must resolve the problem of integrating many different kinds of evidence (Flanagan, 1992). Here we have considered theories from sources as diverse as cognitive psychology, individual differences, brain mechanisms, identity formation at the levels of the individual and the culture, the psychology of social contact, and evolutionary theory to account for the observation that things from early adulthood are learned best and evaluated more positively. Although a scheme of reducing it to a common language remains, the cognitive framework adopted here is adequate for the task.

There is considerable evidence that things learned in early adulthood are preferred and are remembered best. A theory based on fundamental principles of cognitive psychology developed in the laboratory can account for this phenomenon and for enhanced memory during other transitions from rapid change to stability. Changes in basic cognitive abilities over the lifespan do not decline rapidly enough to account for the bump in any simple way. Theories based on identity formation, social contacts, and evolution can be seen as functioning through the mechanisms of the cognitive theory. What remains is a robust, widespread, common sense phenomenon that memory researchers have hardly studied, a handful of plausible theories from a broad range of theoretical perspectives, and the possibility of devising tests to contrast them.

\section{REFERENCES}

ANDERSON, J. R. (1990). The adaptive character of thought. Hillsdale, NJ: Erlbaum.

Anderson, J, R., \& Schooler, L. J. (1991). Reflections of the environment in memory. Psychological Science, 2, 396-408.

Atkinson, R. C., \& Shiffrin, R. M., (1968). Human memory: A proposed system and its control processes. In K. W. Spence \& J. T. Spence (Eds.), The psychology of learning and motivation: Advances in research and theory (Vol. 2, pp. 90-195), New York: Academic Press.

BAHRICK, H. P. (1979). Maintenance of knowledge: Questions about memory we forgot to ask. Journal of Experimental Psychology: General, 108, 296-308.

BAHRick, H. P. (1984). Semantic memory content in permastore: Fifty years of memory for Spanish learned in school. Journal of Experimental Psychology: General, 113, 1-27.

BARTLETT, F. C. (1932), Remembering: A study in experimental and social psychology. Cambridge: Cambridge University Press.

Belli, R. F., SCHuman, H., \& JaCkson, B. (1997). Autobiographical mistemembering: John Dean is not alone. Applied Cognitive Psychology, 11, 187-209.

Benson, K. A., Jarvi, S. D., Arai, Y., Thielbar, P. R. S., Frye, K. J., \& MCDonald, B. L. G. (1992). Socio-historical context and autobiographical memories: Variations in the reminiscence phenomenon. In M. A. Conway, D. C. Rubin, H. Spinnler, \& W. A. Wagenaar (Eds.), Theoretical perspectives on autobiographical memory (pp. 313-322). Dordrecht: Kluwer.

BJORK, R. A., \& BJoRK, E. L. (1992). A new theory of disuse and an old theory of stimulus fluctuation. In A. Healy, S. Kosslyn, \& R. Shiffrin (Eds.), From learning processes to cognitive processes: Essays in honor of William $K$. Estes (Vol. 2, pp. 35-67). Hillsdale, NJ: Erlbaum.

BORNSTEIN, R. F. (1989). Exposure and affect: Overview and metaanalysis of research, 1968-1987. Psychological Bulletin, 106, 265-289. 
Botwinick, J., \& STORANDT, M. (1974). Memory, related functions and age. Springfield, IL: Charles C. Thomas.

BOTWINICK, J., \& STORANDT, M. (1980). Recall and recognition of old information in relation to age and sex. Journal of Gerontology, 35, 70-76.

Braun, K., \& Rubin, D. C. (in press). The spacing effect depends on an encoding deficit, retrieval, and time in working memory: Evidence from once presented words. Memory.

BRUCE, D. (1985). The how and why of ecological memory. Journal of Experimental Psychology: General, 114, 80-92.

Butters, N., \& Cermak, L. S. (1986). A case study of forgetting of autobiographical knowledge: Implications for the study of retrograde amnesia. In D. C. Rubin (Ed.), Autobiographical memory (pp. 253272). Cambridge: Cambridge University Press.

CARSTENSEN, L. L. (1992). Social and emotional patterns in adulthood: Support for socioemotional selectivity theory. Psychology \& Aging, 7, 331-338.

CARSTENSEN, L. L. (1995). Evidence of a life-span theory of socioemotional selectivity. Current Directions in Psychological Science, 4, 151-156.

Cerella, J. (1985). Information processing rates in the elderly. Psychological Bulletin, 98, 67-83.

Cerella, J. (1991). Age effects may be global, not local: Comment on Fisk and Rogers (1991). Journal of Experimental Psychology: General, 120, 215-223.

Cerella, J., \& Hale, S. (1994). The rise and fall in information-processing rates over the life span. Acta Psychologica, 86, 109-197.

Cerella, J., Poon, L. W., \& Williams, D. M. (1980). Age and the complexity hypothesis. In L. W. Poon (Ed.), Aging in the 1980s: Psychological issues (pp. 332-340). Washington, DC: American Psychological Association.

Cohen, G., Conway, M. A., \& Maylor, E. A. (1994). Flashbulb memories in older adults. Psychology \& Aging, 9, 454-463.

COHEN, G., \& FAUlKNer, D. (1988). Life span changes in autobiographical memory. In M. M. Gruneberg, P. E. Morris, \& R. N. Sykes (Eds.), Practical aspects of memory: Current research and issues. Vol. 1. Memory in everyday life (pp. 277-282). New York: Wiley.

CONWAY, M. A. (1990). Autobiographical memory: An introduction. Milton Keynes, U.K.: Open University Press.

Conway, M. A. (1997). The inventory of experience: Memory and identity. In D. Jodelet, J. Pennebaker, \& D. Paez (Eds.), Political events and collective memories (pp. 21-46). Mahwah, $\mathrm{NJ}$ : Erlbaum.

Conway, M. A., \& Rubin, D. C. (1993). The structure of autobiographical memory. In A. E. Collins, S. E. Gathercole, M. A. Conway, \& P. E. Morris (Eds.), Theories of memory (pp. 103-137). Hove, U.K.: Erlbaum.

Conway, M. A., Rubin, D. C., Spinnler, H., \& Wagenaar, W. A (EDS.) (1992). Theoretical perspectives on autobiographical memory (pp. 495-499). Dordrecht: Kluwer.

CRAIK, F. I. M., \& LOCKHART, R. S. (1972). Levels of processing: A framework for memory research. Journal of Verbal Learning \& Ver bal Behavior, 11, 671-684.

Crovitz, H. F., \& Schiffman, H. (1974). Frequency of episodic memories as a function of their age. Bulletin of the Psychonomic Society, 4, 517-518.

DEMPSTER, F. N., (1988). The spacing effect: A case study in the failure to apply the results of the psychological research. American Psychologist, 43, 627-634.

EriCKSON, E. H. (1950). Childhood and society. New York: Norton.

FITZGERALD, J. M. (1988). Vivid memories and the reminiscence phenomenon: The role of a self narrative. Human Development, 31, 261-273.

FitzGerald, J. M. (1996). Intersecting meanings of reminiscence in adult development and aging. In D. C. Rubin (Ed.), Remembering our past: Studies in autobiographical memory (pp. 360-383). Cambridge, U.K.: Cambridge University Press.

Fitzgerald, J, M., \& LAWrenCE, R. (1984). Autobiographical memory across the life-span. Journal of Gerontology, 39, 692-699.

Flanagan, O. J. (1992). Consciousness reconsidered. Cambridge, MA: MIT Press.

Franklin, H. C., \& Holding, D. H. (1977). Personal memories at different ages. Quarterly Journal of Experimental Psychology, 29, 527-532.

Fredrickson, B. F., \& CARSTENSEN, L. L. (1990). Choosing social partners: How old age and anticipated endings make people more selective. Psychology \& Aging, 5, 335-347.
Fromholt, P., LARSEN, P. \& Larsen, S. F. (1995). Effects of late-onset depression and recovery on autobiographical memory. Journal of Gerontology: Psychological Sciences, 50, 74-81.

Fromholt, P., \& L.ARSEN, S. F. (1991). Autobiographical memory in normal aging and primary degenerative dementia (dementia of the Alzheimer type). Journal of Gerontology: Psychological Sciences, 46, 85-91.

Fromholt, P., \& LARSEN, S. F. (1992). Autobiographical memory and life-history narratives in aging and dementia (Alzheimer type). In M. A. Conway, D. C. Rubin, H. Spinnler, \& W. A. Wagenaar (Eds.), Theoretical perspectives on autobiographical memory (pp. 413-426). Dordrecht: Kluwer.

Galton, F. (1879). Psychometric experiments. Brain, 2, 149-162.

Gardiner, J. M., Craik, F. I. M., \& BirTwistle, J. (1972). Retrieval cues and release from proactive inhibition. Journal of Verbal Learning \& Verbal Behavior, 11, 778-783.

Gergen, K. J., \& Gergen, M. M. (1983). Narratives of the self. In T. R. Sarbin \& K. E. Scheibe (Eds.), Studies in social identity (pp. 254-273). New York: Praeger.

HALE, S., \& MYerson, J. (1995). Fifty years older, fifty percent slower? Meta-analytic regression models and semantic context effects. Aging \& Cognition, 2, 132-145.

Henderson, G., Tomlinson, B. E., \& Gibson, P. H. (1980). Cell counts in human cerebral cortex in normal adults throughout life using an image analysing computer. Journal of the Neurological Sciences, 46, 113-136.

HoLBROOK, M. B. (1993). Nostalgia and consumption preferences: Some emerging patterns of consumer tastes. Journal of Consumer Research, 20, 245-256.

HolbRook, M. B., \& SchindleR, R. M. (1989). Some exploratory findings on the development of musical tastes. Journal of Consumer Research, 16, 119-124.

HowES, J. L., \& KATZ, A. N. (1988). Assessing remote memory with an improved public events questionnaire. Psychology \& Aging, 3, 142-150.

HowES, J. L., \& KaTZ, A. N. (1992). Remote memory: Recalling autobiographical and public events from across the lifespan. Canadian Journal of Psychology, 46, 92-116.

Hunt, R. R., \& Einstein, G. O. (1981). Relational and item-specific information in memory. Journal of Verbal Learning \& Verbal Behavior, 20, 497-514.

Hunt, R. R., \& MCDANiEL, M. A. (1993). The enigma of organization and distinctiveness. Journal of Memory \& Language, 32, 421-445.

HunT, R. R., \& Sмiтh, R. E. (1996). Accessing the particular from the general: The power of distinctiveness in the context of organization. Memory \& Cognition, 24, 217-225.

Hyland, D. T., \& ACKerman, A. M. (1988). Reminiscence and autobiographical memory in the study of the personal past. Journal of Gerontology: Psychological Sciences, 43, 35-39.

JANSARI, A., \& PARKIN, A. J. (1996). Things that go bump in your life: Explaining the reminiscence bump in autobiographical memory. Psychology \& Aging, 11, 85-91.

Jernigan, T. L., Press, G. A., \& Hesselink, J. R. (1990). Methods for measuring brain morphologic features on MRI: Validation and normal aging. Archives of Neurology, 47, 27-32.

Kimble, G. A. (1996). Psychology: The hope of a science. Cambridge, MA: MIT Press.

Kintsch, W., \& van Dijk, T. A. (1978). Toward a model of text comprehension. Psychological Review, 85, 363-394.

Komura, H., Miyake, A., Chen, C., Tanizawa, O., \& Yoshikawa, H. (1992). Relationship of age at menarche and subsequent fertility. European Journal of Obstetrics \& Gynecology \& Reproductive Biology, 44, 201-203.

Landauer, T. K., \& BJork, R. A. (1978). Optimum rehearsal pattern and name learning. In M. M. Gruneberg, P. E. Morris, \& R. N. Sykes (Eds.) Practical aspects of memory: International Conference on Practical Aspects of Memory (pp. 625-632). New York: Academic Press.

LARSEN, S. F. (in press). Memorable books: Recall of reading and its personal context. In M. S. MacNealy \& R. Kreuz (Eds.), Empirical approaches to literature and aesthetics (Advances in Discourse Processes, Vol. 52). Norwood, NJ: Ablex.

LONGMORE, F. J., KNIGHT, R. G., \& LONGMORE, B. E. (1990). A test of remote memory for use with New Zealand subjects. New Zealand Journal of Psychology, 19, 17-23. 
Mackavey, W. R., Malley, J. E., \& Stewart, A. J. (1991). Remembering autobiographically consequential experiences: Content analysis of psychologists' accounts of their lives. Psychology \& Aging, 6, 50-59.

MANNHEIM, K. (1952). The problem of generations. In K. Mannheim, Essays on the sociology of knowledge (pp. 276-322). London: Routledge \& Kegan Paul. (Original work published 1928)

Marslen-Wilson, W. D., \& Teuber, H. (1975). Memory for remote events in anterograde amnesia: Recognition of public figures from news photographs. Neuropsychologia, 13, 353-364.

Menken, J., Trussell, J., \& Larsen, U. (1986). Age and infertility. Science, 233, 1389-1394.

Mergler, N. L., \& Goldstein, M. D. (1983). Why are there old people: Senescence as biological and cultural preparedness for the transmission of information. Human Development, 26, 72-90.

Meudell, P. R., Northen, B., Snowden, J. S., \& Neary, D. (1980) Long term memory for famous voices in amnesic and normal subjects. Neuropsychologia, 18, 133-139.

Moreland, R. L., \& ZaJONC, R. B. (1979). Exposure effects may not depend on stimulus recognition. Journal of Personality \& Social Psychology, 37, 1085-1089.

Noble, C. E., BAKER, B. L., \& Jones, T. A. (1964). Age and sex parameters in psychomotor learning. Perceptual \& Motor Skills, 19, 935-945.

RABBITT, P., \& WINTHORPE, C. (1988). What do old people remember? The Galton paradigm reconsidered. In M. M. Gruneberg, P. E. Morris, \& R. N. Sykes (Eds.), Practical aspects of memory: Current research and issues. Vol. 1. Memory in everyday life (pp. 301-307). New York: Wiley.

RASCH, G. (1960). Probabilistic models for some intelligence and at tainment tests. Copenhagen: Nielsen \& Lydiche.

Riвot, T. (1882). Diseases of memory: An essay in the positive psychology (W. H. Smith, Trans.). New York: Appleton.

RiBOT, T. (1906). Essay on the creative imagination. (A. H. N. Baron, Trans.). Chicago: Open Court Publishing.

Robinson, J. A. (1976). Sampling autobiographical memory. Cognitive Psychology, 8, 578-595.

Robinson, J. A. (1992). First experience memories: Contexts and function in personal histories. In M. A. Conway, D. C. Rubin, H. Spinnler, \& W. A. Wagenaar (Eds.), Theoretical perspectives on autobiographical memory (pp. 223-239). Dordrecht: Kluwer.

Robinson, J. A. (1996). Perspective, meaning, and remembering. In D. C. Rubin (Ed.), Remembering our past: Studies in autobiographical memory (pp. 199-217). Cambridge: Cambridge University Press

RuBiN, D. C. (1982). On the retention function for autobiographical memory. Journal of Verbal Learning \& Verbal Behavior, 21, 21-38.

RuBiN, D. C. (1983). Associative asymmetry, availability, and retrieval. Memory \& Cognition, 11, 83-92.

RuBin, D. C. (ED.) (1986). Autobiographical memory. Cambridge: Cambridge University Press.

RuBIN, D. C. (1989). Issues of regularity and control: Confessions of a regularity freak. In L. W. Poon, D. C. Rubin, \& B. A. Wilson (Eds.), Everyday cognition in adult and later life (pp. 84-103). Cambridge: Cambridge University Press.

Rubin, D. C. (1995). Memory in oral traditions: The cognitive psychology of epic, ballads, and counting-out rhymes. New York: Oxford University Press.

RuBin, D. C. (ED.) (1996). Remembering our past: Studies in autobiographical memory. Cambridge: Cambridge University Press.

Rubin, D. C., \& SCHULKIND, M. D. (1997a). The distribution of autobiographical memories across the lifespan. Memory \& Cognition, 25 859-866.

Rubin, D. C., \& Schulkind, M. D. (1997b). The distribution of important and word-cued autobiographical memories in 20-, 35-, and $70-$ year-old adults. Psychology \& Aging, 12, 524-535.
RUBin, D. C., \& Wenzel, A. E. (1996). One hundred years of forgetting: A quantitative description of retention. Psychological Review, 103, 734-760.

Rubin, D. C., WetZler, S. E., \& Nebes, R. D. (1986). Autobiographical memory across the adult lifespan. In D. C. Rubin (Ed.), Autobiographical memory (pp. 202-221). Cambridge: Cambridge University Press.

Salthouse, T. A. (1991). Mediation of adult age differences in cognition by reductions in working memory and speed of processing. Psychological Science, 2, 179-183.

Salthouse, T. A. (1994a). Aging associations: Influence of speed on adult age differences in associative learning. Journal of Experimental Psychology, Learning, Memory, \& Cognition, 20, 1486-1503.

SALTHOUSE, T. A. (1994b). The nature of the influence of speed on adult age differences in cognition. Developmental Psychology, 30, 240-259.

Salthouse, T. A. (1996). The processing-speed theory of adult age differences in cognition. Psychological Review, 103, 403-428.

Schuman, H., Belli, R. F., \& Bischoping. (1997). The generational basis of historical knowledge. In J. W. Pennebaker, D. Paez, \& B. Rime (Eds.), Collective memories of political events (pp. 47-77). Mahwah, NJ: Erlbaum.

Schuman, H., \& RiEger, C. (1992). Collective memory and collective memories. In M. A. Conway, D. C. Rubin, H. Spinnler, \& W. A. Wagenaar (Eds.), Theoretical perspectives on autobiographical memory (pp. 323-336). Dordrecht: Kluwer.

Schuman, H., Rieger, C., \& Gaidys, V. (1994). Collective memories in the United States and Lithuania. In N. Schwartz \& S. Sudman (Eds.), Autobiographical memory and the validity of retrospective reports (pp. 313-333). New York: Springer-Verlag.

Schuman, H., \& ScotT, J. (1989). Generations and collective memories. American Sociological Review, 54, 359-381.

Sehulster, J. R. (1996). In my era: Evidence for the perception of a special period of the past. Memory, 4, 145-158.

Stewart, A. J., \& Healy, J. M., JR. (1989). Linking individual development and social changes. American Psychologist, 44, 30-42.

Storandt, M., Grant, E. A., \& Gordon, B. C. (1978). Remote memory as a function of age and sex. Experimental Aging Research, 4, 365-375.

Terry, R. D., DeTeresa, R., \& Hansen, L. A. (1987). Neocortical cell counts in normal human adult aging. Annals of Neurology, 21, 530-539.

Tulving, E., \& Pearlstone, Z. (1966). Availability versus accessibility of information in memory for words. Journal of Verbal Learning \& Verbal Behavior, 5, 381-391.

Tulving, E., \& Thomson, D. M. (1973). Encoding specificity and retrieval processes in episodic memory. Psychological Review, 80, 352-373.

TVErsKy, A., \& KahNeman, D. (1973). Availability: A heuristic for judging frequency and probability. Cognitive Psychology, 5, 207-232.

UNDERWOOD, B. J. (1957). Interference and forgetting. Psychological Review, 64, 49-59.

Warrington, E. K., \& Sanders, H. I. (1971). The fate of old memories. Quarterly Journal of Experimental Psychology, 23, 432-442.

WECHSLER, D. (1987). Wechsler Memory Scale-Revised: Manual. San Antonio: Psychological Corporation.

WICKENS, D. D. (1970). Encoding categories of words: An empirical approach to meaning. Psychological Review, 77, 1-15.

Woodcock, R. W., \& Johnson, M. B. (1991). Woodcock-Johnson Psycho-Educational Battery-Revised: Tests of cognitive ability. Allen, TX: DLM Teaching Resources.

Zajonc, R. B. (1968). Attitudinal effects of mere exposure. Journal of Personality \& Social Psychology Monograph Supplements, 9(2, Pt. 2), 1-27.

ZaJONC, R. B. (1980). Feeling and thinking: Preferences need no inferences. American Psychologist, 35, 151-175.

Zola-Morgan, S., Cohen, N. J., \& SQuire, L. R. (1983). Recall of remote episodic memory in amnesia. Neuropsychologia, 21, 487-500. 